\title{
Un dibujo de Felipe Berrojo para la portada de San Benito de Sahagún
}

Ramón Pérez de Castro

RESUMEN. La fachada de San Benito de Sahagún es uno de los pocos vestigios conservados del antiguo monasterio benedictino. Presentamos un dibujo preparatorio para la obra realizado por el maestro Felipe Berrojo de Isla hacia 1661. A pesar de su carácter proyectual es un claro exponente de la forma de construir y pensar la arquitectura a mediados del siglo XVII, fuertemente influenciado por el clasicismo pero anunciador de un nuevo sistema barroco del "resurgir del ornato"

Palabras clave: San Benito de Sahagún, Felipe Berrojo, monacato benedictino, portada, siglo XVII.

ABSTRACT. The façade of St. Benito in Sahagún is one of the few conserved vestiges of the ancient benedictine monastery. Now, it's presented a preparatory draw for the work made by the master Felipe Berrojo de Isla arround 1661. In spite of its projectual character is a clear example on the way of build and think the architecture in the middle of the XVII century, strongly influencied by the Clasicism but announcing the new Baroque system of "reappear of the ornament".

Key words: San Benito de Sahagún, Felipe Berrojo, benedictine monasticism, XVII century.

La grandeza histórica de lo que fue Real Monasterio de San Benito de Sahagún únicamente se puede apreciar hoy a través de algunos vestigios que, aunque venerables, no son más que un ligero recuerdo de lo que un día fue y desapareció para siempre. De entre ellos destaca muy especialmente la fachada titulada de San Benito, una construcción barroca que se apoyaba sobre los últimos tramos de la nave de la Epístola del desaparecido templo medieval. Hoy aparece como una portada monumental que, paradójicamente, no da acceso a ningún lugar más que a lo que estamos obligados a imaginar que era el templo de tan singular cenobio, madre de la reforma cluniacense en Castilla. En los últimos años la fachada ha sido restaurada y estudiada de forma monográfica por varios historiadores que recogen la copiosa bibliografía anterior sobre ésta y otras partes del antiguo monasterio, y a los que nos remitimos para no extendernos más de lo debido en este asunto ${ }^{1}$. Todos ellos han puesto sufi-

*Agradezco la colaboración de Jesús, Juan Carlos, Isabel y María Eugenia.

${ }^{1}$ F. HeRAs GARCÍA, “Felipe Berrojo y la portada de la iglesia del Monasterio de Sahagún", BSAA, t. XXXVI, 1970, pp. 503-505; recientemente hay que destacar los trabajos de Ma . D. CAMPOS SÁNCHEZBORDONA, "La reforma del Monasterio de San Benito en la Edad Moderna" y "El malogrado intento de restauración en el siglo XIX", en El Patrimonio artístico 
cientemente en valor una fachada que, desde luego, se nos presenta inconexa, descontextualizada, de la que no se conoce más que el autor y la fecha de ejecución, no por los esclarecedores datos documentales, cuyos secretos aún siguen guardando los archivos, sino porque su constructor, el maestro Felipe Berrojo, se aseguró de imprimirlos en la misma obra² .

Con el presente artículo pretendemos dar a conocer el único documento de archivo encontrado hasta el momento al respecto. Se trata de un pequeño dibujo que tiene más de esbozo y rasguño proyectual que de traza definitiva. Fue perfilado por Felipe Berrojo entre los meses finales de $1660 \mathrm{y}$ junio de 1661, lo más probable en $1661^{3}$. Que tiene un carácter de apunte nos lo indica tanto el trazo suelto del dibujo como el hecho de que haya sido reutilizado por el propio Berrojo como carta de pago de una obra que había ejecutado en la localidad de Villada (Palencia). Por otro lado, al dibujar

de San Benito de Sahagún: esplendor y decadencia de un monasterio medieval, León, 2000; o del profesor R. DoMÍNGUEZ CASAS, "La portada de Felipe Berrojo y la fachada de la portería en el monasterio de San Benito de Sahagún. Estructura e Iconografía", Anales de Arquitectura, núm. 8, 1998, pp. 45-64; "Significado de la portada de Felipe Berrojo en el Real Monasterio de San Benito de Sahagún", Iacobus, núm. 3-4, 1997, pp. 111130; y finalmente del mismo, "El arco de San Benito de Sahagún: Restauración y hallazgos artísticos", Restaurar la Memoria. Congreso Internacional Valladolid ARPA 2000 (actas), Valladolid, 2001, pp. 557-574. Además, E. MORÁIS VALLEJO, Aportación al Barroco en la provincia de León. Arquitectura religiosa, León, 2000, pp. 228-234.

${ }^{2}$ Fue el profesor Martín González el primero en reparar en la inscripción que se lee en las metopas del friso del ático: "FA CIE BAT PHE LIPE BE RO JO, con el dibujo de un compás abierto en la metopa central, en J. J. MARTín GONZÁLEZ, Escultura barroca castellana, Madrid, 1959, p. 53. Esta no fue la única vez que el maestro, uno de los más afamados de su momento en esta zona, dejaba clara su orgullosa autoría, y así en la iglesia de Santiago de Medina de Rioseco, sobre el coro y en grandes letras indica "EL $\mathrm{M}^{\circ}$ - BROJO IZO LAS BํVEDAS, 1673".

${ }^{3}$ Archivo Histórico Provincial de Palencia (AHPPa), Protocolo 2708, fols. 345-381, dibujo en fol. 372v. el maestro un alzado con su planta correspondiente y medidas nos habla de un diseño susceptible de ser llevado a ejecución, como realmente ocurrió, de ahí las analogías entre el dibujo y la obra de la fachada de San Benito que analizaremos más adelante.

En 1656 don Luis de Bárcena, vecino de Villada y sucesor del mayorazgo que fundó el canónigo Antonio Rodríguez de Aguilar acude a la justicia de esta localidad palentina muy próxima a Sahagún exponiendo que las casas donde vive, situadas en la Plaza Mayor de la villa y denominadas "del pozo de Aguilar", se estaban hundiendo por el desplome de la bodega. Para ello se apoya en la declaración del alarife y maestro de obras Alonso Díez. El alcalde pide entonces información a don Jerónimo de Baraona, su hermano y sucesor quien, por boca de su curador se niega a que el reparo corra a cuenta de ningún bien del mayorazgo, pues a su entender, la culpa era del citado don Luis y de su desidia en el cuidado de la bodega; nombra como maestro por su parte a Pedro Santos (9 de marzo de 1658). En diciembre de ese año los maestros de obras Alonso Díez, Blas Díez y Roque Santos, todos vecinos de Villada hacen un listado de los arreglos a efectuar consistentes en "todos los cimientos de albañilería de asta y media, cerrándola de bóveda de asta y media para que se reciba la carga de la casa por estar debajo della, sobre la cual dicha bóveda se ayan de hacer los pilares necesarios para rescivir el dicho quarto que salgan de ladrillo sobre la que se ha de fundar la carpintería sobre sus soleras muy fuertes que se han de poner sobre los pilares donde tocare y para hacer dicha carpintería y aderezar dicho cuarto se ha de desacer todo lo que está al presente arruinado y todo lo demás que fuere necesario cerrando con los vuelos con quien lindare, los emplentes de media asta que a de ser de adove y madera, lo cual se ha de formar y hacer en la misma planta que traía, recivir los tejados y vuelos y atajos de repartimientos de piezas todo muy fuerte echando guellas de varro y capeando los emplentes de 
dentro y de fuera y los tejados ayan de llevar las maderas convenientes y se han de poner las puertas y ventanas necesarias". Presupuestan el trabajo en unos 6.000 reales, a satisfacer con la venta de algunas tierras del mayorazgo, como finalmente se concede $(9$ de abril de 1661). Es precisamente en este momento, el 16 de mayo de 1661 en el que Felipe Berrojo de Isla hace postura en la obra de las casas conforme a las condiciones anteriores, poniéndola en 5.500 reales y 200 más, de prometido. Continúan en el protocolo notarial una serie de cartas de pago de Juan Rodríguez, oficial u obrero que asistió a la obra y, finalmente, sendas cartas de pago de Felipe Berrojo y Vicente Labellano (Avellano) que reutilizan el papel del diseño ${ }^{5}$. A través de ellas queda clara la relación de Berrojo con el dibujo del reverso así como la fecha tope en la que se ejecutó (22 de junio de 1661), cronología que concuerda perfectamente con la de la fachada benedictina. Podemos añadir que a Felipe Berrojo se le intitula vecino de Carrión, y que al menos en esta obra actúa con un Vicente de Labellano maestro de obras vecino de Pámanes.

${ }^{4}$ AHPPa, id. fol. 371: “Recibí yo Juan Rodriguez vecino desta villa de Juan Martínez vecino della 50 reales de vellón por tantos me libró el susodicho don Luis de Varaona y a mi se me devían de mi trabajo de asistir a la obra de la casa que está por quenta de Felipe Berrojo maestro de carpintería y por no saber firmar rrogue a Andrés Puertas y lo firmó por mí. Villada y julio a 13 de 1661".

${ }^{5}$ AHPPa, id. fol. 372. "digo yo phelipe berrojo de isla maestro de obras y becino de la villa de carrion que recibi del Sr Juan Martínez Cuesta 224 reales por quenta de la obra que corre por mi cuenta en las casas de don luis de baraona y por berdad que los recibi di este recibo en villada a 22 de junio de 1661 años. Felipe Berrojo de Isla".

"digo yo vicente Labellano maestro de obras vecino del lugar de pamanes que e rescibido del señor Juan Martínez Cuesta cien Reales por cuenta de phelipe vojo de Isla y por que valga doy este recivo en Villada a 24 de junio. Vicente de Lavellano".

Una línea más abajo "mas recibí 74 reales para pagar hun poco de cal. Vicente de Lavellano".
En el dibujo realizado por Felipe Berrojo para la portada de Sahagún aparecen varias medidas y la nota "obra de san benito de Sagun; ancho 88 pies; alto 60 pies en todo; ¿?vulto 9 pies; gueco del arco de medio punto 22 pies". El esquema responde claramente al modelo de fachada clasicista, fiel heredero de los diseños vignolescos y podría hacerse enlazar con todo el sistema de composición clasicista, ejemplificándose en obras concretas que guardan cierto parecido, como el proyecto de Juan de Herrera para la fachada de la catedral de Valladolid, la fachada de la iglesia vallisoletana de San Agustín o, por relaciones laborales del maestro, con la fachada de la iglesia de Santa Cruz de Medina de Rioseco, reinterpretación de la fachada vignolesca del Gesú que Berrojo indudablemente conocía y para la que labrará sus bóvedas apenas tres años después de realizado el presente dibujo. Esta lista de filiaciones podría ampliarse considerablemente ya que hay que ver en el dibujo más que una influencia de obras concretas, a un maestro como Felipe Berrojo, plenamente inmerso en un ambiente clasicista cuyo lenguaje se había convertido en el auténtico y verdadero modo de pensar y proyectar la arquitectura hasta en sus propios rudimentos. Este dibujo muestra precisamente esos rudimentos arquitectónicos previos, de ahí una de las facetas de su interés, al constituir un raro apunte previo para la distribución de la fachada.

Igualmente, hay que tener presente que la portada que construyó finalmente posee algunos elementos bien diferentes que indican una evolución notable hacia un sentido más barroco, dentro sin embargo, de la contención clásica postherreriana. La primera diferencia clara es la proporción entre el primer y segundo cuerpo: mientras que en el dibujo guardan una relación armónica, teniendo el cuerpo central y superior el mismo ancho, a la forma más clásica, apeando las pilastras del segundo sobre las del primero, en el caso de la portada de 
Sahagún el segundo cuerpo se reduce, cobrando un sentido casi de remate; sus pilastras corintias se hacen más pequeñas y apoyan dos de ellas a plomo sobre las pilastras inferiores pero otras dos, las interiores, lo hacen sobre ménsulas. Los aletones del dibujo, que abarcaban las calles laterales, se reducen ahora considerablemente, siendo sustituidos por sendas balaustradas. Las bolas clasicistas aparecen en los mismos lugares pero bien diferentes de tamaño. El frontón placado y abierto con un óculo no aparece en el dibujo, y las hornacinas laterales sólo se muestran esbozadas, sostenidas por mensulillas y no con el desarrollo de hornacinas con frontón roto y pilastras cajeadas de la construcción pétrea. Por no hablar, por supuesto, de los detalles escultóricos (los reyes no aparecen en el diseño, lo mismo que las formas vegetales de mar$\cos$ y enjutas). Esto se debe a que el dibujo es un mero rasguño preparatorio para la obra de Sahagún. Cuando Berrojo se plantea su construcción, o al menos el diseño definitivo, se ve en la imposibilidad de mantener esas proporciones e incluso las medidas proyectadas, entre otras cosas porque el propio edificio medieval al que tenía que anteponer la fachada guardaba unas proporciones propias, y así puede verse en la huella que se ha mantenido en la cara posterior de la propia portada (rosetas, taqueados, restos de cubriciones...). Así, el ancho de la fachada proyectada y de la construida varían en unos tres metros, y la luz del arco central en poco más de 50 centímetros, variaciones no tan expresivas si tenemos en cuenta la provisionalidad del dibujo que presentamos.

Determinados elementos relacionan estilísticamente el boceto y la fachada de San Benito: en el dibujo está claramente marcada la composición general, las dobles pilastras flanqueando el cuerpo central, el gran escudo en el centro del remate, las hornaci- nas laterales, los aletones o las bolas clasicistas. Aparece incluso la solución dada al interior de ese gran arco central cuya gran luz ha llamado la atención a los historiadores. Ese gran arco cobijaba en origen, como en tantos edificios de la época, la verdadera portada en sí, compuesta por una puerta rectangular y sobre ella una hornacina coronada por un frontón a la manera típicamente clasicista, elementos todos estos que serían suprimidos en el siglo XIX con el fin de facilitar la circulación rodada.

Recientemente se ha puesto en duda la autoría de esta fachada de San Benito, argumentándose que probablemente se trate de la fachada de la portería, trasladada a este lugar en el siglo XIX en el momento de las reformas de fray Miguel Echano, para dar mayor magnificencia a la zona del nuevo crucero $^{6}$. Sin embargo, existen diferentes aspectos que nos hacen disentir de esta opinión, tales como que la fachada de la portería tenía, según las condiciones de su contrato, dos cuerpos y un tercero a modo de remate, que en el primero se abriesen sendas ventanas, gárgolas en forma de cabezas... que no vemos en esta fachada de San Benito, que por otro lado aparece fechada y firmada en el año 1662 por Berrojo, lo cual se corresponde perfectamente con el dibujo que presentamos. Además existen algunos detalles como es el hecho de la presencia del escudo del reino de Portugal formando parte del emblema de Felipe IV, lo mismo que la utilización de las cruces de Avis y Cristo, órdenes portuguesas cuya utilización tendría plena razón de ser en esa fecha de 1662. La inclusión de estos emblemas en la fachada de la portería, construida

\footnotetext{
${ }^{6} \mathrm{M}^{\mathrm{a}}$. D. CAMPOS SÁNCHEZ-BORdONA, "La reforma del monasterio de San Benito...", pp. 206-210. La fachada fue trazada por Pedro Ezquerra, quien se obliga en 1678 a su realización junto a Andrés del Hoyo. Al año siguiente ambos traspasan su ejecución a Juan del Campo. Miguel de Agüero y Dionisio de Pumera se encargarían de la labor escultórica.
} 
en 1678 , no tendría sentido ya que después de la derrota de Ameixal y la firma del Tratado de Lisboa (1668), España había reconocido la independencia del reino luso ${ }^{7}$. Sí es cierto que esta fachada de San Benito influiría notablemente en el resto de las ejecutadas en el cenobio tanto en el mismo siglo XVII (portería) como siglos después; así el padre Echano en el siglo XIX diseña la portada de los pies, flanqueada entre torres de una forma semejante ${ }^{8}$.

Ateniéndonos a todo esto y sobre todo a la comparación directa entre lo esbozado proyectualmente y lo ejecutado, puede decirse que Felipe Berrojo se muestra como un arquitecto de cuño clasicista que, sin embargo, impone en la obra final ciertos elementos de un estilo más avanzado, un juego de elementos y proporciones foráneos a la ortodoxia de los órdenes clásicos, imprimiendo un sentido fuertemente propagandístico y civil. Este avance hacia lo barroco en sus fachadas suele pasar desapercibido, sobre todo cuando se comparan con sus interiores, ejemplos del "resurgir del ornato" $^{\prime \prime}$. Esta aparente contradicción que ha sido planteada tradicionalmente al estudiar su obra no es tal, sobre todo si tenemos en cuenta que para la decoración de las bóvedas, de formas vegetales ampulosamente labradas, carnosas y policromadas de múltiples tonos, Berrojo deja su ejecución en manos de ensambladores y tallistas, que son precisamente los que incorporan a la arquitectura toda la nueva carga ornamen-

7 R. DOMínguez CASAS, “Significado de la portada...", pp. 129-130. Agradezco al autor esta puntualización.

${ }^{8}$ E. ZARAGOZA PASCUAL, "Planos y reedificación de la iglesia del monasterio de san Benito de Sahagún (1824-1831)", Archivos Leoneses, núms. 83-84, 1988, pp. 363-385.

9 J. J. MARTín GONZÁLEZ, Arquitectura barroca vallisoletana, Valladolid, 1967, p. 91. tal prechurrigueresca ${ }^{10}$. Berrojo se consolida entonces como un verdadero arquitectodecorador que dirige un amplio número de maestros autónomos a los que reúne para la realización de obras concretas (maestros de obras, canteros, ensambladores, escultores, policromadores y doradores), como puede verse perfectamente en una de sus grandes producciones, la iglesia de Santiago de Medina de Rioseco. La diferencia estriba en que la decoración de sus bóvedas tienen más de labor de talla y ensamblaje en yeso que de ornamentación arquitectónica en sí, como pudieran ser los florones y cogollos de la fachada benedictina, llevada a cabo por alarifes y canteros, de ahí que se muestren mucho menos jugosos, más contenidos y secos. Este es el origen de esa "contradicción existente entre el arquitecto propiamente dicho y el decorador que había en Felipe Berro$j 0^{\prime \prime 1}$.

\footnotetext{
${ }^{10}$ Sobre esta colaboración entre el Berrojo arquitecto y director de la decoración y los ensambladores y tallistas que ejecutan los motivos ornamentales puede verse R. PÉREZ De CASTRO, "Actividad artística y talleres de ensamblaje en Medina de Rioseco (16501675). LUCAS GONZÁLEZ", BSAA, t. LXVI, 2000, pp. 270-290.

${ }^{11}$ F. HERAS GARCÍA, “Felipe Berrojo y la portada....", p. 503.
} 

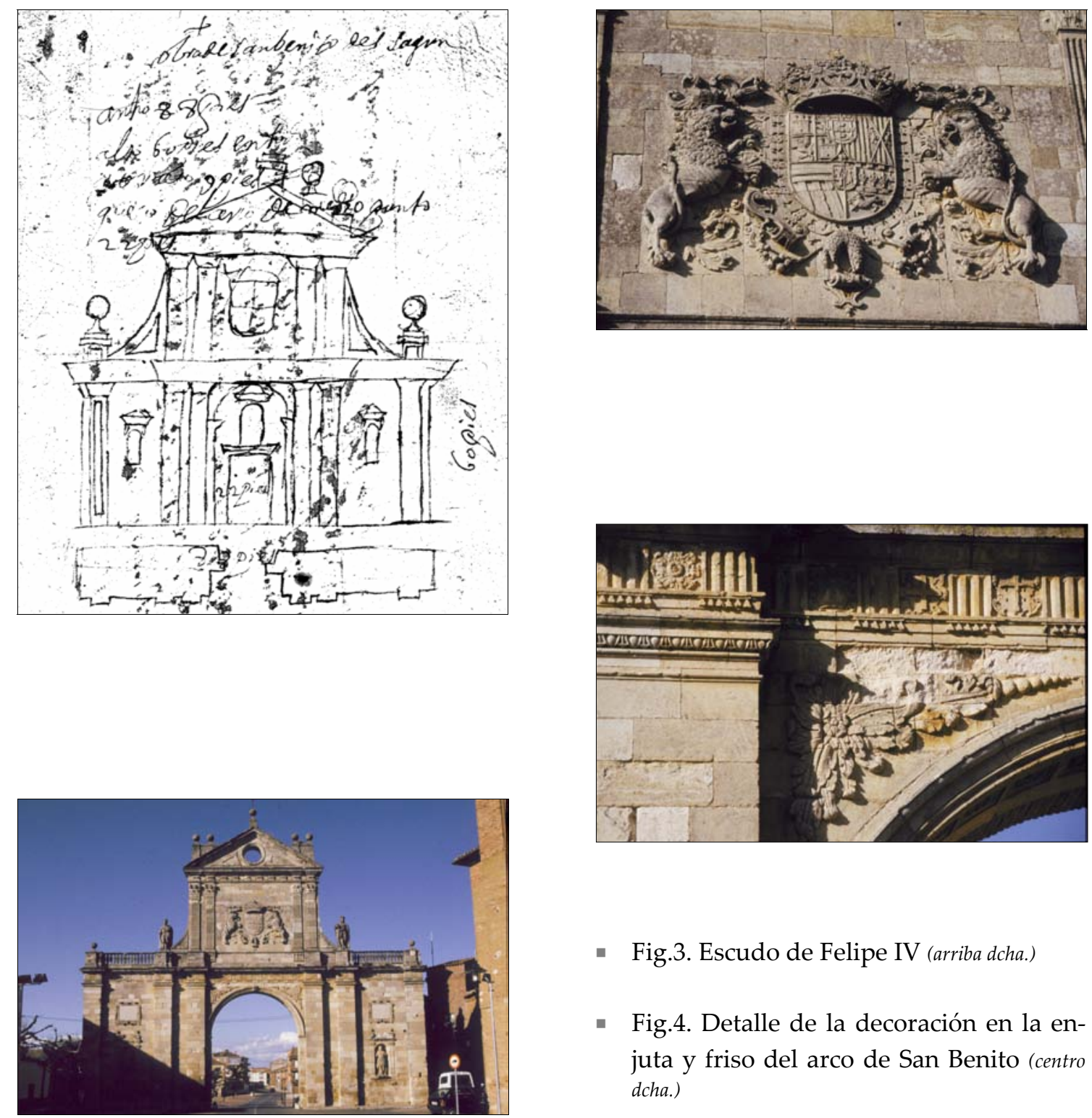

- Fig.3. Escudo de Felipe IV (arriba dcha.)

- Fig.4. Detalle de la decoración en la enjuta y friso del arco de San Benito (centro dcha.)

- Fig.1. Dibujo de Felipe Berrojo para la fachada de San Benito de Sahagún (Archivo Hco. Prov. de Palencia) (arriba izda)

- Fig.2. Fachada del monasterio de San Benito de Sahagún (centro izda.) 